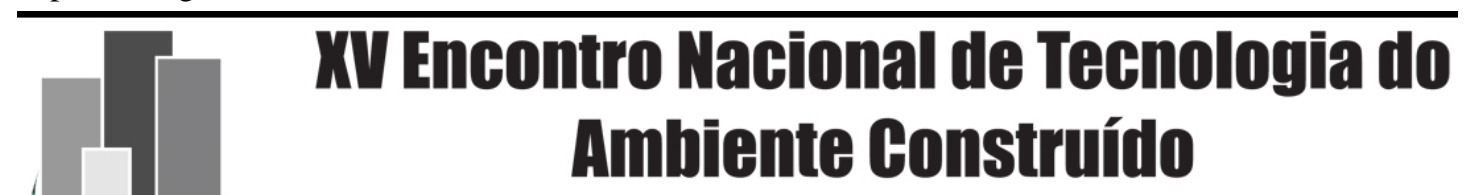

Avanços no desempenho das construções - pesquisa, inovação e capacitação profissional

EVTAL 12, 13 E 14 DE NOVEMBRO DE 2014 | MACEIÓ | AL

\title{
COMPORTAMENTO MECÂNICO DE COMPÓSITO CIMENTÍCIO REFORÇADOS COM FIBRAS DE PAPEL KRAFT
}

SALES, Diego de Castro (1); CABRAL, Antônio Eduardo Bezerra (2)

(1) Universidade Federal do Ceará, e-mail: diegocs86@yahoo.com.br (2) Universidade Federal do Ceará, e-mail: eduardo.cabral@ufc.br

\begin{abstract}
RESUMO
A cadeia produtiva da Construção Civil engloba vários segmentos, findando todos eles em grandes impactos ao meio-ambiente. As embalagens de cimento, por exemplo, são resíduos abundantes em todas as obras, que, por se tratarem de resíduos da CLASSE B (CONAMA, 2002), deveriam ter como destino final a reciclagem ou os depósitos de armazenagem temporária; porém, na realidade, seu descarte nem sempre é feito de maneira apropriada. Este artigo é parte de uma pesquisa de mestrado na qual, considerando-se que práticas sustentáveis devem ocorrer sistemicamente, levantou-se a hipótese de que a fibra do papel Kraft poderia reforçar a composição da matriz cimentícia, a fim de se avaliar seus potenciais usos. Para tanto, optou-se pela aplicação em placas de fibrocimento: componente prático e flexível, utilizado potencialmente para vedação vertical, sem função estrutural. O objetivo deste artigo, logo, é analisar o comportamento mecânico de um compósito cimentício, reforçado por fibras naturais de papel kraft, oriundas de embalagens de cimento descartadas. O método da pesquisa é de cunho experimental e, em seu procedimento, produziram-se placas (corpos de prova), adotando-se três traços de distintos percentuais, em massa, para presença da fibra: o primeiro (referência) sem adição de fibras e os outros dois com $6 \%$ e $12 \%$. Os materiais utilizados para a produção dos corpos de prova foram o cimento Portland (CP V - ARI), a água, o pó calcário e a fibra do papel kraft. A análise do compósito contou com os ensaios de resistência à tração na flexão, de densidade aparente, de permeabilidade, de absorção de água e de variação dimensional imersão/secagem, todos definidos pela norma NBR 15498:2007. O compósito não atingiu a maioria dos requisitos exigidos pela norma. Desses, quando observadas a densidade, a permeabilidade e a variação dimensional, percebeu-se que há um potencial para maiores estudos que permitam o desenvolvimento do material.
\end{abstract}

Palavras-chave: Compósito cimentício; Papel Kraft; Embalagens de Cimento.

\begin{abstract}
The production of Civil Construction chain covers several segments and results in major impacts to the environment. The cement packaging, for example, is an abundant waste in all constructions that, as CLASS $B$ residues (CONAMA, 2002), should be recycled or deposited in temporary storages; in fact, this disposal is not always done properly. This article is part of a Master thesis that considers that sustainable practices should occur systemically. It rose the hypothesis that fiber Kraft paper could enhance the composition of the cement matrix in order to evaluate its potential uses. To accomplish this goal, the study opted for kraft application in fiber cement boards: practical and flexible component, potentially used for vertical sealing with no structural function. The purpose of this article, therefore, is to analyze the mechanical behavior of a composite cement, reinforced by natural fibers - kraft paper - derived from discarded packaging of cement. The research method applied has experimental nature. It was produced plates (specimens), adopting three dashes of different percentage, by mass, of fiber content: the first (reference specimen) has no fiber content, but the other two is filled with $6 \%$ and $12 \%$ of fiber, respectively. The materials used for the production of the specimens were Portland cement (CPV - ARI), water, limestone dust and fiber kraft paper. The analysis of the composite includes tests of tensile strength in bending, bulk density, permeability, water absorption and dimensional variation immersion/drying, all defined by the NBR 15498:2007 (Brazilian standards). The composite has not reached yet most of the requirements demanded by the
\end{abstract}


standard. However, when it comes from density, permeability and dimensional variation, there is a potential for higher studies about the material's development.

Keywords: Cementitious composite; Kraft paper; Cement packaging..

\section{INTRODUÇÃ̃O}

Atualmente, vivencia-se um processo de elevada produção de resíduos, sejam eles industriais, urbanos ou especiais. Atribui-se o crescimento desses rejeitos ao aumento do consumo de materiais de difícil degradação, potencialmente agressivos ao homem e ao meio-ambiente. Segundo Cabral (2007), todas as atividades humanas produzem sobras ou restos, e seu número, em volume, é bastante considerável; por isso, necessitam de uma destinação final apropriada. Os resíduos sólidos - RS merecem atenção, pois representam uma parcela substancial do montante de material descartado e, quando dispostos incorretamente, acarretam problemas sanitários e ambientais.

De acordo com a NBR 10004:2004, considerando os riscos potenciais ao meio ambiente e à saúde pública, os resíduos sólidos classificam-se em: classe I - perigosos, classe II não perigosos (IIA - não inertes e IIB - inertes).

Dentre os grandes geradores de resíduos, encontra-se a cadeia produtiva da Construção Civil. Este setor, fundamentalmente, engloba vários outros segmentos que, de modo similar, findam em grandes impactos ao meio-ambiente. Isso ocorre pois, durante o processo produtivo, registram-se percentuais elevados de perda. Sabe-se, ainda, que pouco desse material é reincorporado à obra ou transformado em insumos para outros setores. Embora esses segmentos atuem distintamente, existe uma preocupação geral, cujos principais objetivos são o descarte, a coleta e a destinação final dos resíduos sólidos. Os materiais provenientes do descarte da indústria da Construção Civil são chamados de Resíduos de Construção e Demolição - RCD. Segundo a ABRELPE (2013), no ano de 2012 foram geradas 62.730 .096 toneladas de resíduos sólidos urbanos, dos quais foram coletados 35 milhões de toneladas somente de RCD, representando uma média de $56 \%$ do montante produzido. Os dados apontaram ainda que, por dia, na região Nordeste são coletadas 20.932 toneladas de RCD (ABRELPE, 2013).

A gestão desses resíduos é especialmente disposta pela Resolução 307 (CONAMA, 2002). Assim, embalagens de cimento (resíduos abundantes em todas as obras), por se enquadrarem na CLASSE B (CONAMA, 2002), deveriam ter como destino final a reciclagem para outros fins ou os depósitos de armazenagem temporária. Todavia, na realidade, seu descarte raramente é feito de maneira apropriada. Em 2011, somente no Brasil, dados do Sindicato Nacional da Indústria do Cimento - SNIC (2012) demonstraram que foram consumidas cerca de 65 milhões de toneladas de cimento. Desse montante, $77 \%$ corresponde a cimento ensacado, ou seja, 50 milhões de toneladas (SNIC, 2012). Em média, cada embalagem de $50 \mathrm{~kg}$ de cimento pesa $150 \mathrm{~g}$. Levando em consideração o montante de cimento ensacado em 2011, conclui-se que foram utilizadas 1 bilhão de embalagens de cimento, o que representa 150 mil toneladas de papel. Presume-se que quase todo esse material tenha sido descartado na natureza: em lixões, aterros sanitários ou incinerados sem nenhum tipo de tratamento, acarretando em sérios problemas ambientais, como poluição do solo ou dos corpos hídricos.

Evitando minimizar a extração de mais recursos naturais, busca-se, cada vez mais, investigar possibilidades de reciclagem do RCD, aplicando-o como matéria-prima alternativa no próprio setor. Este artigo, a exemplo dessas investigações que consideram as práticas sustentáveis como ações sistêmicas, é parte de uma pesquisa de mestrado na qual levantou-se a hipótese de que a fibra do papel Kraft poderia reforçar a composição 
da matriz cimentícia, a fim de se avaliar seus potenciais usos. Para tanto, optou-se pela aplicação em placas de fibrocimento, considerando-o como componente prático e flexível, utilizado potencialmente para vedação vertical, sem função estrutural.

Os concretos com fibras, por exemplo, são definidos como compósitos, conforme Silva (2002), obtidos a partir da conjugação de, no mínimo, dois componentes ou fases. O resultado desta combinação tem como finalidade a obtenção de um novo produto com características diferentes dos seus constituintes originais, pois o concreto em si, sem as fibras, é um compósito cujas fases principais são a pasta, os poros e os agregados (FIGUEIREDO, 2011). Esses materiais, quando adicionados de fibras, porém, passam a compor somente duas fases: a matriz e as fibras.

No Brasil, por 30 anos, estudos realizados no Centro de Pesquisas e Desenvolvimento da Bahia - CEPED, no Instituto Tecnológico do Estado de Pernambuco - ITEP, na Escola Politécnica da Universidade de São Paulo - EP/USP e no Instituto de Pesquisas Tecnológicas do Estado de São Paulo - IPT (SAVASTANO JR, 2000) contemplaram a produção de pias, telhas, calhas e pequenas caixas d'água a partir da utilização de fibras vegetais como reforço com matrizes de cimento Portland.

A exemplo desses estudos, propõe-se a produção de um compósito cimentício reforçado pelas fibras do papel kraft oriundas de embalagens descartadas de sacos de cimento.

\section{OBJETIVOS}

O objetivo principal deste artigo é analisar o comportamento mecânico de um compósito cimentício reforçado por fibras naturais de papel kraft oriundas de embalagens de cimento descartadas. Como objetivo específico, busca-se entender o comportamento de um material potencialmente reciclável e com reinserção na Construção Civil, mitigando, assim, o acúmulo desse resíduo.

\section{PROJETO EXPERIMENTAL}

\subsection{Materiais}

\subsubsection{Cimento Portland CP-V ARI}

Utilizou-se como aglomerante o cimento Portland CP V de Ata Resistência Inicial - ARI, em sacos de $40 \mathrm{~kg}$, consoante a NBR 5733 (ABNT, 1991). Este tipo de cimento possui características específicas para obtenção de alta resistência inicial já nos primeiros dias de aplicação e, assim, é tratado de forma diferenciada pela ABNT em relação ao cimento

Portland comum. Sua composição em percentual de massa é formada por $95 \%$ a $100 \%$ de clínquer e gesso, assim como de material carbonático de 0 a 5\% (ABNT, 1991).

\subsubsection{Carbonato de Cálcio (Pó Calcário)}

O pó calcário é composto de $95 \%$ de $\mathrm{CaCO}_{3}$. Esse material, conforme Moreira (2012), quando na presença de água, não apresenta reatividade de modo que forme compostos estáveis de atividade aglomerante (atividade pozolânica). Tal afirmação foi comprovada a partir dos seguintes resultados: análises de espectroscopia por fluorescência de raios- $\mathrm{X}$ para sua composição química; ensaio qualitativo do material, através do ensaio de difração dos raios-X, onde se obteve a identificação dos elementos cristalinos, observando se há um pico alargado sob picos cristalinos (halo amorfo) na amostra; e, por último, o ensaio de índice de atividade pozolânica com base na NBR 5752 (ABNT, 2012), tendo como resultado um valor de índice de 64,07\%. 
O trabalho de Moreira (2012) demonstrou a análise da composição química do calcário (Tabela 01) pelo ensaio de espectroscopia por fluorescência de raios-X. A gronulometria, por sua vez, foi realizada através do equipamento Mastersizer 2000-E7, demonstrada na Tabela 02:

Tabela 01 - Composição química do pó calcário.

\begin{tabular}{|c|c|}
\hline Composição Química & Teor em Massa (\%) \\
\hline $\mathrm{SiO}_{2}$ & 0,42 \\
\hline $\mathrm{Al}_{2} \mathrm{O}_{3}$ & 0,17 \\
\hline $\mathrm{Fe} 2 \mathrm{O}_{3}$ & 0,11 \\
\hline $\mathrm{CaO}$ & 55,30 \\
\hline $\mathrm{MgO}$ & 0,52 \\
\hline $\mathrm{SO}_{3}$ & 0,04 \\
\hline $\mathrm{In}_{2} \mathrm{O}_{3}$ & 0,31 \\
\hline $\mathrm{Na}_{2} \mathrm{O}$ & 0,083 \\
\hline $\mathrm{Ag}_{2} \mathrm{O}$ & 0,12 \\
\hline $\mathrm{Perda}$ ao fogo & 42,87 \\
\hline
\end{tabular}

Fonte: Moreira (2012).

Tabela 02 - Caracterização do pó calcário.

\begin{tabular}{|c|c|c|}
\hline Ensaio & Norma & Resultados \\
\hline Diâmetro médio & NBR NM 248:2003 & $\begin{array}{c}23,087 \mu \mathrm{m}(\mathrm{D} 10 \%-1,194 \\
\mu \mathrm{m}, \mathrm{D} 50 \%-5,555 \mu \mathrm{m}, \\
\mathrm{D} 90 \%-62,511 \mu \mathrm{m})\end{array}$ \\
\hline Massa específica & NBR NM 23:2001 & $2,68 \mathrm{~g} / \mathrm{cm}^{3}$ \\
\hline Finura & NBR NM 76:1998 & $6230 \mathrm{~cm}^{2} / \mathrm{g}$ \\
\hline Teor de umidade & NBR NM 24:2003 & $0,09 \%$ \\
\hline Perda ao fogo & NBR NM 18:2004 & $42,87 \%$ \\
\hline
\end{tabular}

Fonte: Moreira (2012).

\subsubsection{Fibra do papel Kraft}

Um dos tipos de embalagem utilizadas na comercialização do cimento Portland é feito em sacos de papel Kraft de múltiplas folhas. Silva (2013) afirma que as fibras do papel Kraft são alongadas, conferindo uma resistência significativa ao rasgo comparado com outros tipos de papel. Em relação à gramatura, peso da folha de papel por unidade de superfície, expressa em $\mathrm{g} / \mathrm{m}^{2}$, pode variar de 60 a 120 nos sacos de $50 \mathrm{~kg}$ de cimento Portland comercializados. Neste padrão, as embalagens apresentam um peso médio $182,43 \mathrm{~g}$. As fibrilas que compõem esse papel possuem uma ordem de comprimento que chega a $15.000 \AA$ A com diâmetro que vai de $30 \AA$ A e $300 \AA$. A boa resistência mecânica e a alta absorção de umidade são as principais propriedades da celulose. Seu peso molecular é variável e fórmula empírica $\left(\mathrm{C}_{6} \mathrm{H}_{10} \mathrm{O}_{5}\right) \mathrm{n}$, com valor mínimo de $\mathrm{n}$ igual a 200 (que, tipicamente, está entre $300 \leq \mathrm{n} \leq 700$ ), podendo passar de 7000 (MANO, 2004). 


\subsection{Métodos}

O projeto experimental foi desenvolvido em três etapas distintas: a) obtenção da fibra natural a partir dos sacos de cimento (polpação); b) produção do compósito de cimento reforçado pelas fibras natural dos sacos de cimento; c) realização dos ensaios de desempenho mecânico do compósito segundo a NBR 15498 (ABNT, 2007): resistência à tração na flexão, densidade aparente, permeabilidade, absorção de água e variação dimensional por imersão/secagem.

\subsubsection{Obtenção das fibras naturais dos sacos de cimento}

Obteve-se as embalagens descartadas de cimento em obras e em fábricas de pré-moldados de Fortaleza. O procedimento adotado para obtenção dessas fibras naturais seguiu as orientações de Buson (2009), que indica a prévia limpeza dos sacos, retirando o excesso de cimento e os eventuais pedriscos formados a partir da umidade. Essa medida faz-se necessária a fim de não danificar os instrumentos de obtenção da polpa celulósica. Posteriormente, os sacos de cimento foram triturados utilizando-se um Triturador Prensapel Modelo - PL 1400 e, em seguida, recolhidos.

A etapa posterior consistiu no processo de dispersão das fibras do papel Kraft com a imersão em água e trituração (polpação). Manteve-se relação de 150,0 g de sacos de cimento/3,0 kg de água para polpação (BUSON, 2009). Utilizou-se um equipamento adaptado (o hidrapulper), constituído de tambor metálico acoplado a uma hélice, movida por um motor e com um dreno em sua parte inferior conforme a Figura 01.

\section{Figura 01 - Equipamento para polpação das fibras.}

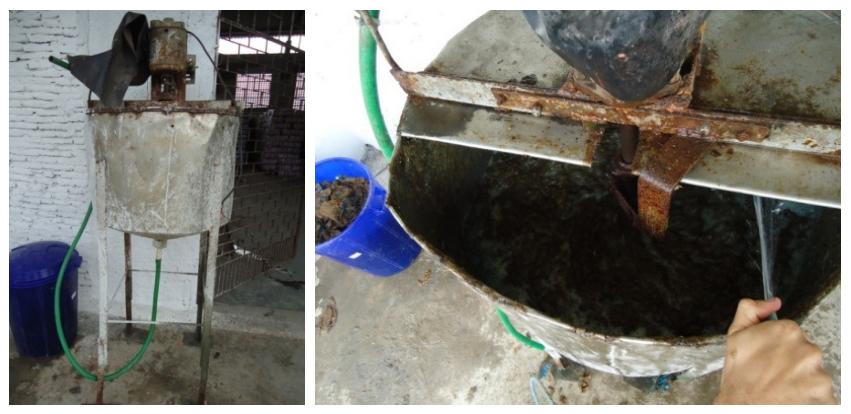

Fonte: Autores (2013).

O composto (embalagem + água) permaneceu em trituração por 10 minutos conforme orientação de Silva (2013). Posteriormente a esse procedimento, retirou-se o excesso de água; para isso, pressionou-se a polpa contra uma tela de serigrafia (Figura 02).

\section{Figura 02 - Drenagem, em tela serigráfica, do excesso de água da polpa celulósica de papel kraft.}

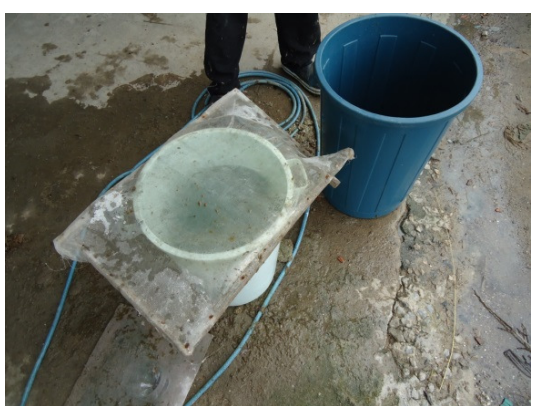

Fonte: Autores (2013).

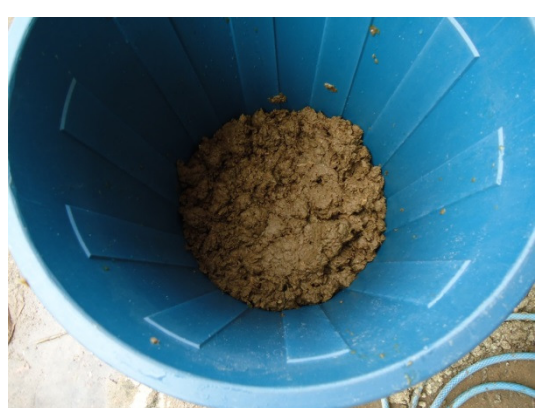




\subsubsection{Fabricação do compósito de cimento reforçado com fibras naturais}

As placas foram produzidas dentro de um molde com as dimensões $220 \mathrm{~cm}$ x $110 \mathrm{~cm}$ x 1 $\mathrm{cm}$ (largura x comprimento x espessura), sendo um total de três placas (uma unidade por traço) (Figura 03).

Figura 03 - Projeto da forma para moldagem das placas.

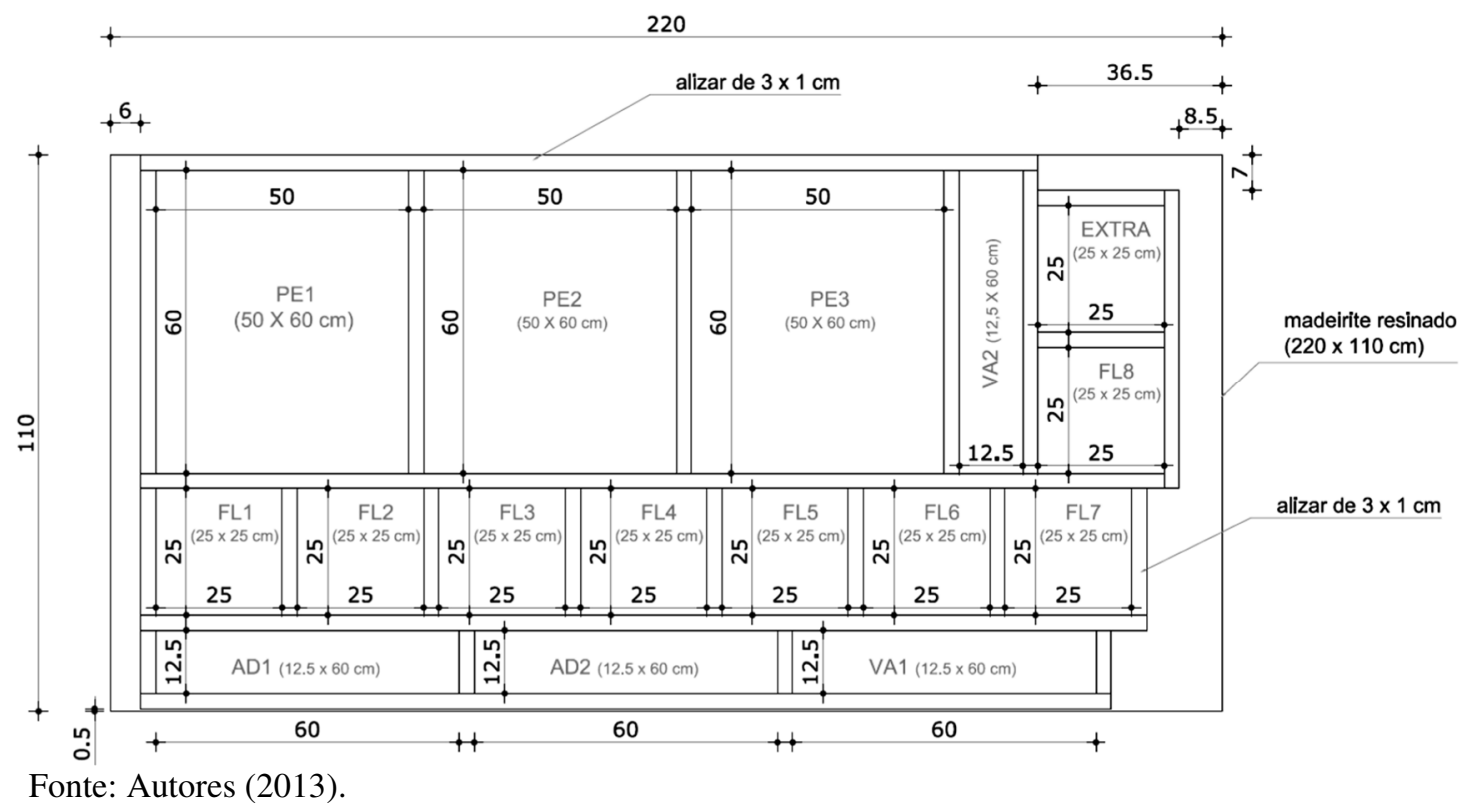

Para a fabricação do compósito de fibrocimento, foram definidos 3 traços distintos, em massa, de cimento Portland $\mathrm{CP}-\mathrm{V}$, Carbonato de Cálcio $\left(\mathrm{CaCO}_{3}\right)$, água e fibra celulósica dos sacos de cimento, a fim de se observar o comportamento das placas com teores distintos de fibra natural em sua composição (Tabela 03).

Tabela 03 - Traços aplicados no compósito.

\begin{tabular}{|c|c|c|c|c|}
\hline \multirow{2}{*}{ Traços } & \multicolumn{3}{|c|}{ Matriz (em massa) } & $\begin{array}{c}\text { Reforço (em } \\
\text { massa) }\end{array}$ \\
\cline { 2 - 5 } & $\begin{array}{c}\text { Cimento CP- } \\
\text { V }\end{array}$ & $\begin{array}{c}\text { Carbonato de } \\
\text { Cálcio } \\
\text { (CaCO }\end{array}$ & $\begin{array}{c}\text { Fator } \\
\text { água/cimento }\end{array}$ & Fibra celulósica \\
\hline Traço-TR 0 & 1 & 1,5 & 1,125 & - \\
\hline Traço-TR 4 & 1 & 1,5 & 1,125 & $4 \%$ \\
\hline Traço-TR 6 & 1 & 1,5 & 1,125 & $6 \%$ \\
\hline
\end{tabular}

Fonte: Autores (2013).

Mesclou-se o conjunto em betoneira com inclinação de $45^{\circ}$ por 20 minutos. A ordem dos materiais foi: $1 / 3$ da água, carbonato de cálcio, cimento $\mathrm{CP}-\mathrm{V}$ e fibra celulósica. Os outros $2 / 3$ da água foram dosados de forma a manter a melhor trabalhabilidade do compósito, levando-se em consideração a soma de dois fatores: fator água-cimento de 0,45 e fator água-CaCO 3 de 0,675. Com isso, obteve-se um fator água-aglomerante de 1,125.

As placas passaram por um período de 28 dias de cura. Após esse período, foram desformadas e passaram por mais 7 dias de repouso para a obtenção do chamado estado de equilíbrio. Posteriormente, foram realizados ensaios de tipo para verificação do 
potencial da pesquisa, os quais seguiram a NBR 15498 - Placa plana cimentícia sem amianto - Requisitos e métodos de ensaio (ABNT, 2007). Os ensaios de tipo verificam a conformidade aos requisitos da norma de produtos novos ou modificados, cujas características não são tradicionalmente conhecidas. Esses ensaios são realizados em 2 tipos de estado: equilíbrio (período de repouso de 7 dias em temperatura ambiente) e saturado (imersos em água por um período de 24 horas).

Os ensaios realizados foram: a) Resistência à tração na flexão; b) Densidade aparente; c) Permeabilidade; d) Absorção de água; e) Variação dimensional por imersão/secagem.

\section{RESULTADOS E DISCUSSÕES}

\subsection{Resistência à tração na flexão}

Os resultados obtidos foram lançados na Tabela 04 abaixo:

Tabela 04 - Resultados do ensaio de flexão no estado de equilíbrio e de saturação.

\begin{tabular}{|c|c|c|c|c|}
\hline \multicolumn{2}{|c|}{ CP's com 25 cm x 25 cm } & \multicolumn{3}{c|}{ Resistência dos traços em Pascal (Pa) } \\
\cline { 2 - 5 } & TR 0 & TR 6 & TR 12 \\
\hline \multirow{4}{*}{$\begin{array}{c}\text { Estado de } \\
\text { Equilíbrio }\end{array}$} & CP 1 & 26 & 256 & 141 \\
\cline { 2 - 5 } & CP2 & 26 & 256 & 141 \\
\cline { 2 - 5 } & CP3 & 256 & 203 & 203 \\
\cline { 2 - 5 } & CP4 & 26 & 203 & 141 \\
\cline { 2 - 5 } & Média & 141 & 229 & 172 \\
\cline { 2 - 5 } & CP 5 & 344 & 141 & 26 \\
\cline { 2 - 5 } & CP6 & 114 & 141 & 52 \\
\cline { 2 - 5 } Estado & CP7 & 141 & 141 & 52 \\
\cline { 2 - 5 } & CP8 & 114 & 88 & 26 \\
\cline { 2 - 5 } & Média & 178 & 114 & 39 \\
\hline
\end{tabular}

Fonte: Autores (2013).

Percebeu-se que, em estado de equilíbrio, a placa que obteve melhor desempenho foi a placa produzida com $6 \%$ em massa de fibra celulósica (TR 6). Já em estado saturado, seu desempenho reduziu em uma média de $49,78 \%$. A placa sem o reforço de fibras foi a placa que sofreu menos variação de resistência entre os diferentes estados, além ainda de apresentar o melhor resultado dentre as placas no estado saturado, com $178 \mathrm{~Pa}$. Se comparados com a exigência da norma, os rendimentos foram bastante insatisfatórios, da ordem de $10^{-6}$ vezes inferiores

\subsection{Densidade aparente}

Os resultados encontrados foram dispostos na Tabela 05 .

Tabela 05 - Densidades aparentes no estado de equilíbrio e de saturação.

\begin{tabular}{|l|c|c|c|c|}
\hline \multicolumn{2}{|c|}{ CP's com 12,5 cm x 30cm } & \multicolumn{3}{c|}{ Densidade aparente ( $\rho)$ em g/cm } \\
\cline { 3 - 5 } \multicolumn{2}{|c|}{} & TR 0 & TR 6 & TR 12 \\
\hline \multirow{2}{*}{$\begin{array}{l}\text { Estado de } \\
\text { Equilíbrio }\end{array}$} & CP 1 & 1,69 & 1,10 & 0,98 \\
\cline { 2 - 5 } & CP2 & 1,76 & 1,22 & 0,90 \\
\hline
\end{tabular}




\begin{tabular}{|c|c|c|c|c|}
\hline \multirow{7}{*}{} & CP3 & 1,56 & 1,07 & 0,96 \\
\cline { 2 - 5 } & CP4 & 1,46 & 0,95 & 1,03 \\
\cline { 2 - 5 } & Média & 1,62 & 1,09 & 0,98 \\
\hline \multirow{4}{*}{$\begin{array}{c}\text { Estado } \\
\text { Saturado }\end{array}$} & CP 1 & 2,01 & 1,48 & 1,36 \\
\cline { 2 - 5 } & CP2 & 2,13 & 1,47 & 1,42 \\
\cline { 2 - 5 } & CP3 & 1,91 & 1,57 & 1,39 \\
\cline { 2 - 5 } & CP4 & 1,75 & 1,04 & 1,40 \\
\cline { 2 - 5 } & Média & 1,95 & 1,39 & 1,39 \\
\hline
\end{tabular}

Fonte: Autores (2013).

Os corpos de prova quando submetidos aos ensaios de densidade obtiveram resultados satisfatórios. Em estado saturado, a placa TR 6 apresentou densidade semelhante à placa com teor de $12 \%$ de fibras (TR 12).

\subsection{Permeabilidade}

A norma estabelece que se considere aceitável a ocorrência de manchas na superfície inferior das placas, porém não se admite a formação de bolhas. Dentre os 9 corpos-deprova testados, as peças retiradas das placas de traço TR 0 e TR 12 apresentaram comportamentos aceitáveis. Os corpos retirados da placa TR 6 apresentaram bolhas em sua superfície inferior, não obtendo assim a aceitabilidade exigida pela norma. Todas as placas fabricadas foram permeáveis, embora duas amostras tenham atendido.

\subsection{Absorção de água (w)}

As placas fabricadas pelo experimento obtiveram altos índices de absorção de água. Foram registrados, em média, índices superiores a 200\%, demonstrados na Tabela 06 abaixo.

Tabela 06 - Resultados de absorção de água.

\begin{tabular}{|c|c|c|c|c|}
\hline \multicolumn{2}{|c|}{ CP's com 12,5 cm x 30cm } & \multicolumn{3}{|c|}{ Absorção de água $(\mathbf{W})$} \\
\cline { 3 - 5 } & TR 0 & TR 6 & TR 12 \\
\hline \multirow{3}{*}{$\begin{array}{c}\text { Estado } \\
\text { Saturado }\end{array}$} & CP 1 & $218,9 \%$ & $234,3 \%$ & $237,8 \%$ \\
\cline { 2 - 5 } & CP2 & $220,9 \%$ & $221,0 \%$ & $257,7 \%$ \\
\cline { 2 - 5 } & CP3 & $222,0 \%$ & $244,9 \%$ & $245,0 \%$ \\
\cline { 2 - 5 } & CP4 & $220,1 \%$ & $209,5 \%$ & $236,2 \%$ \\
\cline { 2 - 5 } & Média & $220,5 \%$ & $227,5 \%$ & $244,2 \%$ \\
\hline
\end{tabular}

Fonte: Autores (2013).

Apresentou, porém, a melhor média de absorção (menor absorção), a placa fabricada sem o reforço de fibras TR 0 .

\subsection{Variação dimensional por imersão e secagem (v)}

Os ensaios de variação dimensional por imersão e secagem apresentaram resultados satisfatórios. Todas as placas atenderam os requisitos exigidos pela norma, quando submetidas às situações extremas. Segue abaixo a Tabela 07, demonstrando essas variações. 
Tabela 07 - Resultados de variação dimensional.

\begin{tabular}{|c|c|c|c|c|}
\hline \multicolumn{2}{|c|}{ CP's com 12,5 cm x 30cm } & \multicolumn{3}{|c|}{ Variação dimensional (V) } \\
\cline { 2 - 5 } & TR 0 & TR 6 & TR 12 \\
\hline \multirow{3}{*}{$\begin{array}{c}\text { Estado } \\
\text { Saturado }\end{array}$} & CP 1 & 0 & 0 & $1 \%$ \\
\cline { 2 - 5 } & CP2 & 0 & 0 & 0 \\
\cline { 2 - 5 } & CP3 & 0 & 0 & $1 \%$ \\
\cline { 2 - 5 } & CP4 & 0 & $1 \%$ & 0 \\
\cline { 2 - 5 } & Média & 0 & $0,25 \%$ & $0,5 \%$ \\
\hline
\end{tabular}

Fonte: Autores (2013).

\section{CONSIDERAÇÕES FINAIS}

O experimento possibilitou observar o comportamento das novas placas, porém os resultados foram bastante divergentes em relação aos requisitos exigidos pela norma NBR 15498. O ensaio de resistência à tração na flexão demonstrou que todas as placas do experimento apresentaram comportamento bastante insatisfatório, da ordem de $10^{-6}$. Quanto à densidade aparente, os resultados foram compensadores, obtiveram-se placas de densidade inferior à matriz, quando reforçadas pelas fibras. Duas placas, TR 6 e TR 12, também apresentaram, em estado saturado, densidades iguais entre si. Todas as placas produzidas foram permeáveis, porém TR 6 não atingiu os requisitos exigidos pela norma, apresentando a formação de bolhas de água na superfície inferior. Em consequência da permeabilidade, verificaram-se altos índices de absorção entre todas as placas. A média entre as placas foi superior a $200 \%$. O ensaio de variação por imersão e secagem apresentou-se satisfatório, visto que as variações atingiram a amplitude de $0-0,5 \%$. Essa amplitude é considerada aceitável pela norma.

Em síntese, o compósito não atingiu a maioria dos requisitos exigidos pela norma, tendo em vista que o método corrente de obtenção das fibras por meio da dispersão em água não permite que se obtenha um material com baixo teor de umidade. $O$ excesso de umidade das fibras e a inadequação (sobre o traço) na correção de água para a melhoria da trabalhabilidade do compósito influenciaram na queda de resistência do cimento. Desta maneira, acrescenta-se a necessidade de se revisar os métodos de obtenção das fibras que reduza o teor de umidade da matéria-prima, uma vez que, quando observadas a densidade, a permeabilidade e a variação dimensional apresentadas, percebe-se que há um potencial para maiores estudos que permitam o desenvolvimento apropriado do material.

\section{REFERÊNCIAS}

ASSOCIAÇÃO BRASILEIRA DAS EMPRESAS DE LIMPEZA PÚBLICA E RESÍDUOS ESPECIAIS - ABRELPE. Resíduos Sólidos: Manual de Boas Práticas no Planejamento. São Paulo. 108p. 2013. Disponível em $<$ http://www.abrelpe.org.br/arquivos/manual_portugues_2013.pdf>.

ASSOCIAÇÃO BRASILEIRA DE NORMAS TÉCNICAS. NBR 5733: Cimento Portland Com Alta Resistência Inicial. Rio de Janeiro, 1991. 5p.

NBR 5752: Materiais pozolânicos — Determinação de atividade pozolânica com cimento Portland - Índice de atividade pozolânica com cimento — Método de ensaio. Rio de Janeiro, 2012. 4p. 
NBR 10004: Resíduos sólidos — Classificação. Rio de Janeiro, 2004. 71p.

NBR 15498: Placa plana cimentícia sem amianto - Requisitos e métodos de ensaio. Rio de Janeiro, 2007. 26p.

BUSON, Márcio Albuquerque. Kraftterra: Desenvolvimento e análise preliminar do desempenho térmico de componetes de terra com a incorporação de fibras de papel kraft provenientes da reciclagem de sacos de cimento para vedação vertical. $\sim 135$ p. Tese (Doutorado) - Faculdade de Arquitetura e Urbanismo, Universidade de Brasília, 2009.

CABRAL, A.E.B. Modelagem de propriedades mecânicas e de durabilidade de concretos produzidos com agregados reciclados, considerando-se a variabilidade da composição do RCD. 280p. Tese (Doutorado em Ciências da Engenharia Ambiental) Escola de Engenharia de São Carlos, Universidade de São Paulo, São Carlos, 2007.

CONSELHO NACIONAL DO MEIO AMBIENTE - CONAMA. Resolução no. 307, de 05 de julho de 2002. Diretrizes e procedimentos para gestão de resíduos da construção. Brasília: MMA/CONAMA, 2002.

FIGUEIREDO, Antônio Domingues. Concreto reforçado com fibras. Tese (Livredocência) - Escola Politécnica, Universidade de São Paulo, São Paulo, 2011.

MANO, Eloisa Biasotto. Introdução a polímeros. São Paulo: Blücher, 2.ed. rev. e ampl. 2004.

MOREIRA, Kelvya Maria De Vasconcelos. Concreto Autoadensável Com Agregados Graúdos Reciclados De Concreto, 2012. Dissertação (Mestrado) - Universidade Federal do Ceará, Programa de Pós-Graduaçăo em Engenharia Civil: Estruturas e Construção Civil. Fortaleza, 2012.

SAVASTANO JR, H. Materiais à base de cimento reforçados com fibra vegetal: reciclagem de resíduos para a construção de baixo custo. Tese (Livre-docência) Escola Politécnica, Universidade de São Paulo, São Paulo, 2000.

SILVA, Aluizio Caldas. Estudo da durabilidade de compósitos reforçados com fibras de celulose. 2002. Dissertação (Mestrado em Engenharia de Construção Civil e Urbana) - Escola Politécnica, Universidade de São Paulo, São Paulo, 2002. Disponível em: $<$ http://www.teses.usp.br/teses/disponiveis/3/3146/tde-05112002-172710/>. Acesso em: 2013-05-22.

SILVA, Myrtes Amaral Da. Obtenção e caracterização de compósitos cimentícios reforçados com fibras de papel de embalagens de cimento. Dissertação (Mestrado) Centro Federal de Educação Tecnológica de Minas Gerais, Programa de Pós-Graduação em Engenharia de Materiais, Belo Horizonte, 2013.

SINDICATO NACIONAL DA INDÚSTRIA DO CIMENTO - SNIC. Relatório Anual de 2012. Disponível em:<http://www.snic.org.br/pdf/relatorio_anual_201213_web.pdf >. Acesso em: 02/09/2013. 